centrifugation to give the proteoglycan subunit fraction (Hascall \& Sajdera, 1969).

Dilute solutions of $\mathrm{LaCl}_{3}(0.5 \mathrm{M}, 13.0)$ solubilized $80 \%$ of the total cartilage protein-polysaccharide. $\mathrm{CeCl}_{3}$ gave a similar result. $\mathrm{MgCl}_{2}(3.0 \mathrm{M}, 19.0)$, $\mathrm{CaCl}_{2}(2.0 \mathrm{M}, I 6.0), \mathrm{LiCl}(6.0 \mathrm{M}, I 6.0)$ and guanidinium chloride $(4.0 \mathrm{M}, 14.0)$ also extracted about $80 \%$ of the protein-polysaccharide present, but at higher ionic strength.

Analysis of the proteoglycan subunit fraction obtained from the $\mathrm{LaCl}_{3}$ extract showed that its protein content, uronic acid content and amino acid composition were very similar to those of the proteoglycan obtained by extraction with the other salts mentioned above. It also showed similar behaviour on electrophoresis at $\mathrm{pH} 3.0$ and 7.0 in a sucrose density gradient (R. M. Mason \& R. W. Mayes, unpublished work).

Recent histochemical evidence has suggested that $\mathrm{La}^{3+}$ may be used at low concentration $(23 \mathrm{mM})$ as an electron stain for demonstrating acidic proteinpolysaccharides in tissues (Shea, 1971). It is noteworthy therefore that, although cartilage chondroitin sulphate protein-polysaccharides are solubilized at one concentration of $\mathrm{LaCl}_{3}$, they are completely precipitated from solution when the salt concentration is lowered to $50 \mathrm{~mm}$ by either dilution or dialysis. This suggests that the basis for histochemical staining of acidic protein-polysaccharides in the tissues is the formation of an insoluble complex between $\mathrm{La}^{3+}$ and the anionic polysaccharides at low concentrations of $\mathrm{La}^{3+}$.

We thank the Nuffield Foundation for financial support.

Bitter, T. \& Muir, H. (1962) Anal. Biochem. 4, 330

Doganges, P. T. \& Schubert, M. (1964) J. Biol. Chem. 239, 1498

Hascall, V. C. \& Sajdera, S. W. (1969) J. Biol. Chem. 244, 2384

Mason, R. M. \& Wusteman, F. S. (1970) Biochem. J. 120, 777

Shea, S. M. (1971) J. Cell Biol. 51, 611

\section{Aggregation of Cartilage Proteoglycans}

By C. P. Tsiganos, ${ }^{*}$ T. E. Hardingham and Helen MUIR (Division of Biochemistry, Kennedy Institute of Rheumatology, London W6 7DW, U.K.)

Proteoglycans of bovine nasal septum have been shown to undergo a reversible aggregation that was induced by a 'glycoprotein link fraction', which was separated from the proteoglycan by equilibrium density-gradient centrifugation in $4 \mathrm{M}$-guanidinium chloride (Hascall \& Sajdera, 1969).

* Present address: Marika Eliadi Maternity Hospital, 2 East Venizelos Square, Athens (606), Greece.
Previous work (Tsiganos \& Muir, 1970; Tsiganos et al., 1971) has shown that the disaggregation of proteoglycans was accompanied by a large decrease in apparent size on gel chromatography. The reversible aggregation of proteoglycan has now been examined further.

Proteoglycans were extracted from pig laryngeal cartilage with $4 \mathrm{M}$-guanidinium chloride and purified by equilibrium density-gradient centrifugation. Samples were further fractionated by equilibrium density-gradient centrifugation in $4 \mathrm{M}$-guanidinium chloride in an MSE 65 centrifuge $(8 \times 25 \mathrm{ml}$ angle rotor) at $95000 \mathrm{~g}_{\mathrm{av} .}$ for $48 \mathrm{~h}$ at $20^{\circ} \mathrm{C}$ (Tsiganos et al., 1971).

Three fractions were taken, and the distribution of the total uronic acid and protein respectively was as follows: bottom fraction (B), 97.4 and $57.4 \%$; middle fraction (M), 1.0 and $5.2 \%$; top fraction $(\mathrm{T}), 1.6$ and $37.4 \%$.

Gel chromatography on Sepharose 2B showed that half the starting material was excluded from the gel, whereas the disaggregated proteoglycan in fraction B was of much smaller average size and only $14.4 \%$ was excluded from the gel. To find in which fraction the component inducing aggregation might be, fractions were remixed under disaggregating conditions and in the same relative proportions in which they occurred in the extract. After dialysis, when reaggregation should occur, they were again compared by gel chromatography. The mixing of fraction $M$ or fractions $M$ and $T$ with fraction $B$ produced a large change in size to give a profile similar to that of starting material. In contrast, when fractions $B$ and $T$ were mixed there was little change in elution profile, although the protein in fraction $\mathrm{T}$ became bound to the proteoglycan. Thus fraction $M$ and not $T$ promoted aggregation, and this was confirmed in proteoglycans from a variety of sources including bovine nasal cartilage. Hascall \& Sajdera (1969), however, found that aggregation was promoted by the 'glycoprotein link fraction', which corresponds to fraction $T$. This discrepancy may be due to different conditions of centrifugation. The present results showed that the protein-rich fraction $T$ was not essential for aggregation. The aggregating component was present in a fraction that was more than half carbohydrate in composition and accounted for less than $1.5 \%$ of the proteoglycan starting material.

Hascall, V. C. \& Sajdera, S. W. (1969) J. Biol. Chem. 244, 2384

Tsiganos, C. P. \& Muir, H. (1970) in Chemistry and Molecular Biology of the Intercellular Matrix (Balazs, E. A., ed.), vol. 2, p. 859, Academic Press, New York and London

Tsiganos, C. P., Hardingham, T. E. \& Muir, H. (1971) Biochim. Biophys. Acta 229, 529 